\title{
Triophthalmia and facial clefting: a case report
}

\author{
S M Tayel, M A Sabry, N Abdel Kader, S Farah, S A Al-Awadi, T I Farag
}

\begin{abstract}
We describe a Libyan boy with an unusual phenotype of multiple congenital anomalies, including triophthalmia, dolichocephaly, porencephaly, cleft lip/palate, facial asymmetry, micrognathia, and VSD. The reported phenotype is likely to represent a new entity of nonchromosomal syndromic triophthalmia. Other possibilities are discussed.

(F Med Genet 1998;35:875-877)
\end{abstract}

Keywords: triophthalmia; facial clefting

The formation of additional eyes in animals has recently been achieved through experimental genetic manipulations. ${ }^{12}$ The human eye develops from the optic primordium at about 4 the formation of the optic vesicle/cup from the forebrain which gives rise to the retina. The somatic ectoderm is in turn induced by the optic vesicle giving rise to the lens, which then induces the formation of the corneal epithelium from somatic ectoderm. ${ }^{3}$ Several genes involved in the regulation of eye development have now been identified, including the mouse Pax6 gene, which is believed to play a master role in triggering the development of eye components. ${ }^{1}$ The development of the eye is also under the influence of several growth factors, for example, the nerve growth factor and transforming growth factor $\beta .^{3}$ Retinoic acid

Kuwait Medical

Genetics Centre,

Kuwait

S M Tayel

M A Sabry

S A Al-Awadi

Department of Histology and

Genetics, Great Al-Fateh University for Medical Science, Tripoli, Libya N A Kader

\section{Neurology}

Department, IbnSina Hospital, Kuwait S Farah

Dalhausie University, Halifax, Canada T I Farag

Correspondence to: Dr Sabry, 4 Channel Close, Rhoose, Vale of Glamorgan CF62 3EH, UK.

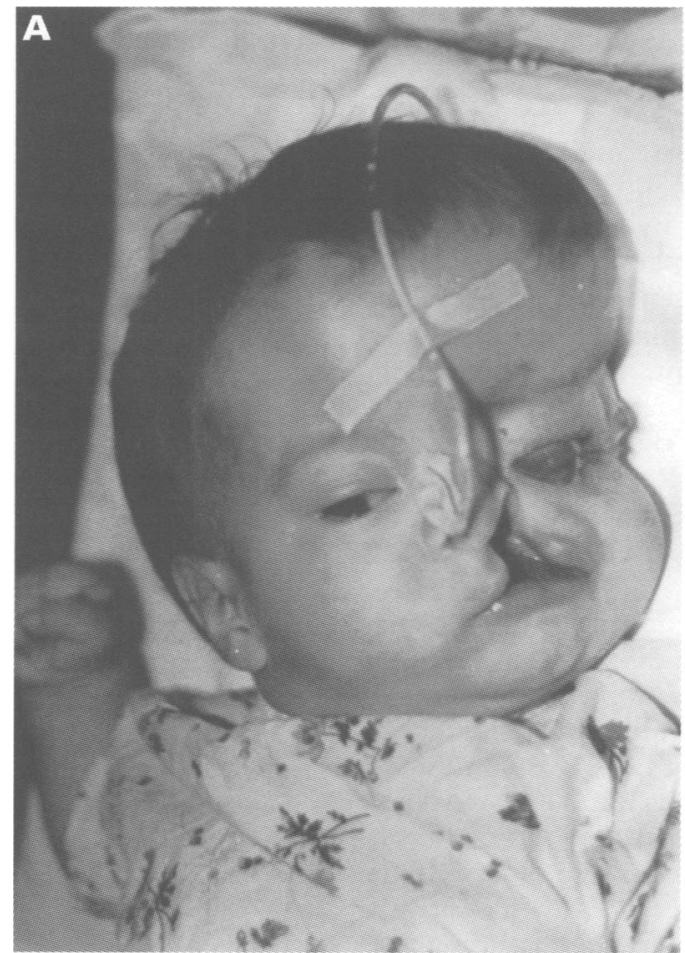
weeks' gestation. The neural ectoderm induces

and its receptors also represent key molecules in the development of the eye $e^{4}$ that, in high concentrations, have recently been shown to induce duplication of eye components in animals. ${ }^{2}$ The proband in the present report had unusual craniofacial dysmorphism with a unique phenotype of syndromic nonchromosomal triophthalmia. The phenotype, which is likely to represent a new syndrome, is critically discussed with emphasis on the possible causal mechanism.

\section{Case report}

The proband was a male, delivered at term by caesarian section because of macrocephaly. The pregnancy was uneventful and there was no history of drug intake or exposure to irradiation, infection, or teratogens during the pregnancy. The Libyan parents and the 3 year old older sister were phenotypically normal. At 6 months of age the proband's weight was 4800 g ( $<3$ rd centile), length $54 \mathrm{~cm}$ ( $<3$ rd centile), and head circumference (OFC) $44 \mathrm{~cm}$ (50th centile). The baby had dolichocephaly and a prominent, asymmetrical forehead with a widow's peak. The left eye was larger than the right eye with a downward slanting left palpebral fissure, hypoplasia/ectropion of the left lower eyelid, and corneal opacity. The right microphthalmic eye had intact extraocular muscular movements and normal vision. An additional third eye was noted on the left temporal side with a complete globe, upper/lower lids, and

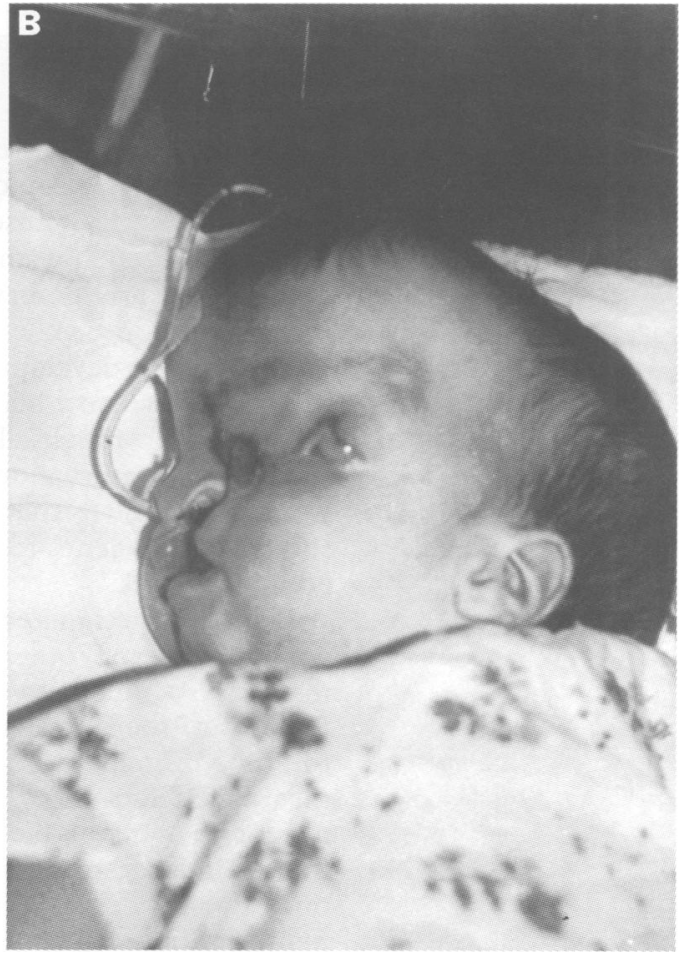

Figure 1 Photographs of the proband showing facial dysmorphism and triophthalmia. 
lashes, extraocular muscles, and lacrimal apparatus (fig 1). The right eyebrow was normally placed while the left eyebrow extended above both the left eye and the supernumerary third eye. There was a left sided complete cleft lip/palate with hypoplasia of the left nasal ala and deformed left nostril. The ears were low set and posteriorly angulated. The baby had micrognathia and his face was asymmetrical with a more prominent left cheek and more posteriorly rotated left ear (fig 1). He was fed by nasogastric tube, had no vomiting, and his growth and speech development were appropriate for age. He could hear and respond to sounds by turning his head towards the appropriate side. All four limbs, back, spine, and genitalia were normal and there was no abnormality detected on chest and abdominal examination. A left parasternal murmur was clinically detected over the 3rd and 4th intercostal spaces, which was confirmed by echocardiography to be related to the presence of VSD. Examination of the nervous system showed intact sensation, normal muscle power, tone, and reflexes with a positive grasp reflex, age appropriate Babiniski response, normal tendon jerks, and absence of clonus. Head CT scan showed porencephaly, dilated ventricles, and brain atrophy. A defective left maxilla was shown on skull $x$ ray. Chromosomal study with banding techniques indicated that the child had a normal male karyotype $(46, \mathrm{XY})$ while a urine spot test and TLC for amino acids and mucopolysaccharides showed normal/negative results. The child died at the age of 6 months after reconstructive surgery for his cleft lip/ palate. No necropsy was attempted.

\section{Discussion}

The unique craniofacial malformation described here is characterised by the presence of syndromic triophthalmia associated with dolichocephaly, porencephaly, brain atrophy, cleft lip/palate, micrognathia, and VSD. In humans, an additional ectopically placed eye has been described in only one previous report. ${ }^{5}$ The profile in the present report, in addition to the previous report, ${ }^{5}$ could well represent a new syndromic entity caused by a mutation in a pleiotropic gene of the patterning hierarchy involved in early embryogenesis. Of particular interest are those genes implicated in the regulation of eye development, of which several members have now been identified in different species with a remarkable degree of structural/ functional conservation. ${ }^{1}$ Recent experimental work has shown that ectopic expression of some of these genes results in the formation of additional eyes. ${ }^{12}$

Before we designate the described phenotype a new syndrome, other possible causal mechanisms also need to be considered. Some features of the reported profile show similarity to the human homologue of the mouse disorganisation (Ds, MIM 223200). ${ }^{6}$ In the mouse, the phenotypic expression of the mouse mutant Disorganisation gene is so diverse that no two affected mice have identical malformations. ${ }^{7}$ The developmental anomalies associated with $D s$ involve structures derived from all three germ layers. ${ }^{8}$ The mutation is semidominant with variable peneterance, depending on the genetic background of the mice, and is usually lethal in homozygotes. ${ }^{9} \frac{10}{3}$ The anomalies described in $D s$ mice include body surface projections, such as hamartomas $\Omega$ nodules, and papillae. Also seen are supernu merary limbs and anomalies of the extremities? such as duplications and reductions. Body wall defects include gastroschisis and thoracoschisis? and various anomalies of the internal organs. ${ }^{1}$ ? Craniopharyngeal anomalies and eye defects also exist, ${ }^{12}$ although triophthalmia has neve been described before. The abnormal findings of the human homologue of the mouse mutants Disorganisation $(D s)$ have been reviewed in $\vec{p}$ numerous reports. ${ }^{7-9} 13-20$

Features of the reported baby which areू compatible with the diagnosis of $D$ s include the presence of facial asymmetry, cleft lip/palate micrognathia, low set ears, and CNS anomaliess with brain atrophy, porencephaly, and dilate $\dot{5}$ ventricles. ${ }^{621}$ The absence of limb anomaliespo abdominal wall defects, and body projections in the described phenotype makes the diagno- - 을 sis of $D$ s less likely, albeit not totally excluded since limb anomalies were detected in only क third of the $D s$ mice described by Hummel ${ }^{2} \mathrm{H}^{\circ}$ and were absent in the patient reported by Van® Langen and Hennekam. ${ }^{21}$ However, the possi $\overrightarrow{0}$ bility of holoprosencephaly ${ }^{23}$ should not be्巳 considered because of the absence of its characteristic facial features and the lack of brain cleavage disorder on head CT scan.

It is clear that the gene(s) related to the्षी expression of the unusual phenotype of the proband represents an integral part of the pat terning hierarchy involved in early develop옥 ment of the eye, face, and heart.

Oliver G, Gruss P. Current views on eye development. Trends Neurosci 1997;20:415-21.

2 Hyatt GA, Schmitt EA, Marsh-Armstrong NA, Dowing JE Retinoic acid-induced duplication of the zebrafish retina Proc Natl Acad Sci USA 1992;89:8293-7.

3 O'Rahilly R, Muller F, eds. Human embryology and teratology: 2nd ed. New York: John Wiley, 1996.

4 Hyatt GA, Dowling JE. Retinoic acid. A key molecule fo eye and photoreceptor development. Invest Ophthalmol Vis Sci 1997;38:1471-5.

5 Cohen MM Jr. Perspectives on craniofacial asymmetry. Int $\not$ \ا Oral Maxillofac Surg 1995;24:8-12.

6 McKusick VA. Mendelian inheritance in man. 12th ed Baltimore: Johns Hopkins University Press, 1997.

7 Hummel KD. The inheritance and expression of disorganisation, an unusual mutation in the mouse. F Exp Zool 1958 N 137:389-23

8 Wainwright $H$, Viljoen D. Developmental anomalies ir monozygotic twins representing a human homologue for the mouse mutant disorganization. Clin Dysmorphol 1993 2:135-9.

9 Woods CG, Treleaven S, Betheras FR, Sheffield LJ Disorganization-like syndrome with $47 \mathrm{XXY}$ and unilatera每 narrowing of the common iliac artery. Clin Dysmorphot 1995;4:82-6.

10 Elliott AM, Chen MF, Azouz EM, Teebi AS. Developmen tal anomalies suggestive of the human homologue of the mouse mutant disorganization. Am $¥$ Med Genet 1995;55: 240-3. 1 Robin NH, Adewale OO, McDonald-McGinn D, Nadeal JH. Human malformations similar to those in the mous

12 Crosby JL, Varnum DS, Washburn LL, Nadeau JH. Disor ganization is a completely dominant gain of function mouse mutation causing sporadic developmental defects

Mech Dev 1992;37:121-6.
13 Donnai D, Winter RM. Disorganisation: a model for 'earlyamnion rupture'. $\mathcal{F}$ Med Genet 1989;26:421-5.

14 Winter RM, Donnai D. A possible human homologue for the mouse mutant disorganisation. $\mathcal{F}$ Med Genet 1989;26: 417-20.

$15 \mathrm{Lin} \mathrm{AE}$. Two additional patients representing the possible human homologue for the mouse mutant disorganisation (Ds). F Med Genet 1991;28:645-7. 
16 Lowry RB, Yong SL. Cleft lip and palate, sensorineural deafness, and sacral lipoma in two brothers: a possible example of the disorganisation mutant. F Med Genet 1991; 28:135-7.

17 Naguib KK, Hamoud MS, Khalil ES, El-Khalifa MY. Homologue for the mouse mutant disorganisation. Does it exist? F Med Genet 1991;28:138-9.

18 Petzel MA, Erickson RP. Disorganisation: a possible cause of apparent conjoint twinning. $\mathcal{F}$ Med Genet 1991;28:71214.

19 De Michelena MI, Stachurska A. Multiple anomalies possibly caused by a human homologue to the mouse disorganization (Ds) gene. Clin Dysmorphol 1993;2:131-4.
20 Sabry MA, Al-Saleh Q, Al-Sawan R, Al-Awadi SA, Farag TI. Right upper limb bud triplication and polythelia, left sided hemihypertrophy, facial dysmorphism, and congenital heart disease: disorganisation-like spectrum or patterntal heart disease: disorganisation-like spectrum

21 Van Langen IM, Hennekam RC. Another example of the human homologue of the mouse mutant disorganization Clin Dysmorphol 1994;3:361-2.

22 Hummel KD. Developmental anomalies in mice resulting from action of the gene disorganization, a semi-dominant lethal. Pediatrics 1959;23:212-21.

23 Cohen MM Jr. The child with multiple birth defects. 2nd ed. New York: Oxford University Press, 1997. 